\title{
Facile Synthesis of Porous Carbon Nitride Spheres with Hierarchical Three-Dimensional Mesostructures for $\mathrm{CO}_{2}$ Capture
}

\author{
Qiang $\mathrm{Li}^{1}$, Jianping Yang ${ }^{1}$, Dan Feng ${ }^{1}$, Zhangxiong $\mathrm{Wu}^{1}$, Qingling $\mathrm{Wu}^{1}$, Sung Soo Park ${ }^{2}$, Chang-Sik $\mathrm{Ha}^{2}$, and \\ Dongyuan Zhao ${ }^{1}(\bowtie)$ \\ ${ }^{1}$ Department of Chemistry and Shanghai Key Laboratory of Molecular Catalysis and Innovative Materials, Laboratory of Advanced \\ Materials, Fudan University, Shanghai 200433, China \\ ${ }^{2}$ Department of Polymer Science and Engineering, Pusan National University, Geumjeong-gu, Busan 609-735, Korea \\ Received: 18 July 2010 / Revised: 29 July 2010 / Accepted: 29 July 2010 \\ C The Author(s) 2010. This article is published with open access at Springerlink.com
}

\begin{abstract}
Porous carbon nitride $(\mathrm{CN})$ spheres with partially crystalline frameworks have been successfully synthesized via a nanocasting approach by using spherical mesoporous cellular silica foams (MCFs) as a hard template, and ethylenediamine and carbon tetrachloride as precursors. The resulting spherical $\mathrm{CN}$ materials have uniform diameters of ca. $4 \mu \mathrm{m}$, hierarchical three-dimensional (3-D) mesostructures with small and large mesopores with pore diameters centered at ca. 4.0 and $43 \mathrm{~nm}$, respectively, a relatively high BET surface area of $\sim 550 \mathrm{~m}^{2} / \mathrm{g}$, and a pore volume of $0.90 \mathrm{~cm}^{3} / \mathrm{g}$. High-resolution transmission electron microscope (HRTEM) images, wide-angle X-ray diffraction (XRD) patterns, and Raman spectra demonstrate that the porous $\mathrm{CN}$ material has a partly graphitized structure. In addition, elemental analyses, X-ray photoelectron spectra (XPS), Fourier transform infrared spectra (FT-IR), and $\mathrm{CO}_{2}$ temperature-programmed desorption $\left(\mathrm{CO}_{2}\right.$-TPD) show that the material has a high nitrogen content $(17.8 \mathrm{wt} \%$ ) with nitrogen-containing groups and abundant basic sites. The hierarchical porous $\mathrm{CN}$ spheres have excellent $\mathrm{CO}_{2}$ capture properties with a capacity of $2.90 \mathrm{mmol} / \mathrm{g}$ at $25^{\circ} \mathrm{C}$ and $0.97 \mathrm{mmol} / \mathrm{g}$ at $75{ }^{\circ} \mathrm{C}$, superior to those of the pure carbon materials with analogous mesostructures. This can be mainly attributed to the abundant nitrogen-containing basic groups, hierarchical mesostructure, relatively high BET surface area and stable framework. Furthermore, the presence of a large number of micropores and small mesopores also enhance the $\mathrm{CO}_{2}$ capture performance, owing to the capillary condensation effect.
\end{abstract}

\section{KEYWORDS}

Mesoporous materials, carbon nitride, nanocasting, sphere, hard template, $\mathrm{CO}_{2}$ capture

\section{Introduction}

Carbon nitride $(\mathrm{CN})$ has attracted a great deal of attention recently, due to its unique combination of properties, including semiconductivity, extreme hardness, biocompatibility, low density, special optical features, energy-storage capacity, and presence of basic sites [1-4]. These features are responsible for its many applications such as in direct methanol fuel cells, catalysis, photocatalysis, and electron emission devices [5-7]. Compared with bulk samples, mesoporous $\mathrm{CN}$ materials have higher specific surface areas (up to $830 \mathrm{~m}^{2} / \mathrm{g}$ ) and larger porosities (up to $1.25 \mathrm{~cm}^{3} / \mathrm{g}$ ) [8], which results in enhanced performance

Address correspondence to dyzhao@ $@$ fudan.edu.cn 
in such applications due to the larger number of active chemical sites exposed on the surface and the higher size- or shape-selectivity. Therefore, many scientists have focused on the synthesis of mesoporous $\mathrm{CN}$ materials by using different strategies and precursors [8-14]. For example, Vinu et al. [8] reported the synthesis of mesoporous $\mathrm{CN}$ materials based on pyridine- and benzene-ring building blocks by using mesoporous silica SBA-15 as a hard template and ethylenediamine (EDA) and carbon tetrachloride (CTC) as precursors. Cyanamide, dicyandiamide, melamine, EDA, and CTC are commonly used as a nitrogen source for the synthesis of mesoporous $\mathrm{CN}$ materials by the nanocasting approach. However, cyanamide and dicyandiamide are toxic and expensive, which restrict their use in large-scale production. The use of melamine also creates problems in the synthesis process, due to its low sublimation temperature $\left(300^{\circ} \mathrm{C}\right)$ [11]. EDA and CTC are more favorable precursors for the synthesis of mesoporous $\mathrm{CN}$ materials, because of their relatively low costs. It is well known that three-dimensional (3-D) pore channels are more advantageous for mass diffusion than 2-D pores. Unfortunately, the synthesis of 3-D mesoporous CN materials has rarely been reported [15]. In addition, the control of the morphology of such materials is very important in order to improve their performance in practical applications. Although the use of spherical materials can reduce the flow resistance to liquids and improve the utilization efficiency of space, there have been few reports of the synthesis of mesoporous $\mathrm{CN}$ materials with tailored morphologies. Vinu et al. [10] synthesized mesoporous $\mathrm{CN}$ nanoparticles with high nitrogen content and small diameter $(<150 \mathrm{~nm})$ by using silica nanoparticles as a precursor and EDA and CTC as precursors.

Global warming, which mainly results from the emission of greenhouse gases such as $\mathrm{CO}_{2}$ and $\mathrm{CH}_{4}$, continues to attract intense world-wide attention [16, 17]. $\mathrm{CO}_{2}$ is produced as a flue gas in many industrial processes, and in automobile exhausts $[18,19]$. The removal of $\mathrm{CO}_{2}$ from flue gases by a capture process is necessary prior to their release to the atmosphere. Moreover, the capture step accounts for up to threefourths of the total cost of the process [20,21]. Capture processes involving both physical and chemical absorption have been developed. Compared with physical adsorption, the latter has good capture selectivity and high capacity especially at relatively high temperatures, due to the strong chemical interaction between $\mathrm{CO}_{2}$ molecules and sorbents. Currently, large-scale capture of $\mathrm{CO}_{2}$ produced from fossil-fuel combustion is based on sorption by liquid amines such as monoethanolamine, diethanolamine, and methyldiethanolamine. However, these systems have some disadvantages such as poor chemical stability, and mass transport efficiency, corrosion of equipment, toxicity, and flow problems caused by viscosity [21-24]. Recently, nitrogen-functionalized mesoporous silica and carbon materials have been extensively used as a sorbent for $\mathrm{CO}_{2}$-capture, since they do not suffer from these drawbacks and show relatively good performance resulting from the combination of their high surface area and the basicity of nitrogen-containing groups [17, 20-22, 25, 26]. For instance, Zelenak et al. [22] synthesized 3-aminopropylgrafted mesoporous silica SBA-12 which had a $\mathrm{CO}_{2}$ uptake of $1.04 \mathrm{mmol} / \mathrm{g}$ at $25^{\circ} \mathrm{C}$. However, the introduction of nitrogen-containing groups usually gives rise to a decrease in the specific surface area of mesoporous materials, which reduces their capture capacities. Pevida et al. [25] synthesized activated carbon containing $2.1 \mathrm{wt} \%$ of nitrogen by ammonia treatment at $900{ }^{\circ} \mathrm{C}$, which showed capture capacities of 9.6 and $3.2 \mathrm{wt} \%$ at 25 and $75{ }^{\circ} \mathrm{C}$, respectively. This demonstrates that high nitrogen content can result in high $\mathrm{CO}_{2}$ uptake.

Herein, we report a synthesis of hierarchical mesoporous carbon nitride spheres with a diameter of ca. $4 \mu \mathrm{m}$ by using spherical mesostructured cellular silica foams (MCFs) as a hard template, and ethylenediamine and carbon tetrachloride as precursors and investigate the $\mathrm{CO}_{2}$ sorption properties of the resulting products.

\section{Experimental section}

\subsection{Chemicals}

Triblock copolymer poly(ethylene oxide)- $b$ poly(propylene oxide)- $b$-poly(ethylene oxide) (Pluronic P123, EO $\mathrm{EO}_{20} \mathrm{PO}_{70} \mathrm{EO}_{20}, M_{\mathrm{av}}=5800 \mathrm{~g} / \mathrm{mol}$ ) was purchased from Aldrich Chemical Company Inc.

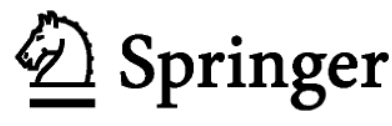


Tetraethyl orthosilicate (TEOS), 1,3,5-trimethyl benzene (TMB), ammonium fluoride, CTC and EDA were purchased from Shanghai Chemical Co. All chemicals were used as received without any further purification. Millipore water was used in all experiments.

\subsection{Synthesis}

\subsubsection{Synthesis of spherical mesostructured cellular silica foams}

The spherical MCFs were synthesized according to the literature [27]. A typical synthesis procedure was as follows: $4.0 \mathrm{~g}$ of Pluronic P123 was dissolved in $75 \mathrm{~mL}$ of $1.6 \mathrm{~mol} / \mathrm{L} \mathrm{HCl}$ solution at room temperature. After the temperature of the mixture was increased to $40{ }^{\circ} \mathrm{C}, 4.0 \mathrm{~g}$ of TMB was added and the mixture was stirred for $2 \mathrm{~h}$. Then, $18.4 \mathrm{~mL}$ of TEOS was added into the above solution which was stirred for $5 \mathrm{~min}$. The mixed solution was subsequently transferred to an autoclave and aged at $40{ }^{\circ} \mathrm{C}$ for $20 \mathrm{~h}$. Then $0.046 \mathrm{~g}$ of $\mathrm{NH}_{4} \mathrm{~F}$ was added, and the mixture was aged at $100{ }^{\circ} \mathrm{C}$ for $24 \mathrm{~h}$. The product was collected by filtration and washed with water and ethanol, and the final material was obtained by calcination at $550{ }^{\circ} \mathrm{C}$ for $5 \mathrm{~h}$ to remove the P123 template.

\subsubsection{Synthesis of mesoporous CN spheres}

The mesoporous $\mathrm{CN}$ spheres were synthesized by using spherical silica MCFs as a hard template. In a typical procedure, $0.30 \mathrm{~g}$ of the silica MCF template was added to a mixed solution containing $1.2 \mathrm{~g}$ of EDA and $2.4 \mathrm{~g}$ of CTC at room temperature. The above solution was then heated at $90^{\circ} \mathrm{C}$ for $6 \mathrm{~h}$ under reflux to induce polymerization of the precursor. The resulting dark-brown mixture was pre-pyrolyzed at $400{ }^{\circ} \mathrm{C}$ for $2 \mathrm{~h}$ in an argon atmosphere. The pyrolyzed sample was refilled with $0.6 \mathrm{~g}$ of EDA and $1.2 \mathrm{~g}$ of CTC at $90{ }^{\circ} \mathrm{C}$. After pyrolysis at $600{ }^{\circ} \mathrm{C}$ for $5 \mathrm{~h}$ in argon, the spherical mesoporous $\mathrm{CN}$ product was obtained by using $5 \mathrm{wt} \% \mathrm{HF}$ aqueous solution to remove the silica template.

\subsubsection{Control experiment}

To investigate the influence of nitrogen-containing groups on $\mathrm{CO}_{2}$-capture performance, pristine mesoporous carbon spheres were also synthesized by using the hard template method mentioned above. $0.4 \mathrm{~g}$ of the silica MCFs was dispersed in $20 \mathrm{~mL}$ of ethanol solution containing $1.0 \mathrm{~g}$ of a resol precursor prepared by the method reported previously (Fig. S-1 in the Electronic Supplementary Material) [28]. After stirring for $10 \mathrm{~min}$ at room temperature, the ethanol solvent was removed by evaporation. The sample was then dried in an oven at $50{ }^{\circ} \mathrm{C}$ to further vaporize the residual ethanol. After pyrolysis at $600{ }^{\circ} \mathrm{C}$ for $2 \mathrm{~h}$, the mesoporous carbon spheres were obtained by using HF solution to remove the silica template.

\section{$2.3 \mathrm{CO}_{2}$-capture performance}

The $\mathrm{CO}_{2}$ uptake of the mesoporous materials was measured by using a thermogravimetric analyzer (DTG-60, Shimadzu Japan). In a typical measurement procedure, the carbon nitride samples were first activated at $350{ }^{\circ} \mathrm{C}$ for $1 \mathrm{~h}$ with a ramping rate of $10{ }^{\circ} \mathrm{C} / \mathrm{min}$ under nitrogen flow gas $(30 \mathrm{~mL} / \mathrm{min})$ to remove any small molecules physically adsorbed. After the temperature was reduced to 25 or $75^{\circ} \mathrm{C}$, the samples were allowed to adsorb $\mathrm{CO}_{2}$ by replacing the $\mathrm{N}_{2}$ gas flow by $\mathrm{CO}_{2}$ with a flow rate of $30 \mathrm{~mL} / \mathrm{min}$. This process was continued for $150 \mathrm{~min}$ to measure $\mathrm{CO}_{2}$ uptake of the sample. The adsorption/desorption cycling performance of the samples was also measured. The samples after adsorption of $\mathrm{CO}_{2}$ were heated at $200{ }^{\circ} \mathrm{C}$ with a ramp rate of $10^{\circ} \mathrm{C} / \mathrm{min}$ in a nitrogen atmosphere and cooled down to $25^{\circ} \mathrm{C}$, and allowed to adsorb $\mathrm{CO}_{2}$ again for $60 \mathrm{~min}$. This process was repeated for three runs to evaluate any changes in $\mathrm{CO}_{2}$ uptake.

\subsection{Characterization}

Small-angle X-ray scattering (SAXS) measurements were carried out on a NanoSTAR small-angle X-ray scattering system (Bruker, Germany) using $\mathrm{Cu} \mathrm{Ka}$ radiation $(40 \mathrm{kV}, 35 \mathrm{~mA})$. Nitrogen sorption isotherms were measured with a Micromeritics Tristar 3020 (USA) analyzer at $77 \mathrm{~K}$. Before measurements, the samples were degassed at $180{ }^{\circ} \mathrm{C}$ in a vacuum for more than $6 \mathrm{~h}$. The Brunauer-Emmett-Teller (BET) method was utilized to calculate the specific surface areas $\left(S_{\mathrm{BET}}\right)$. The pore size distributions were calculated from the adsorption branches of isotherms by using the 
Barrett-Joyner-Halenda (BJH) model. The total pore volumes $\left(V_{\mathrm{t}}\right)$ were estimated from the adsorbed amount at a relative pressure $P / P_{0}$ of 0.995 . Scanning electron microscopy (SEM) images were obtained using a S-4800 field emission microscope (Hitachi, Japan) operated at $1 \mathrm{kV}$. Transmission electron microscopy (TEM) images were recorded on a JEM-2100F microscope (JEOL, Japan) operated at $200 \mathrm{kV}$. Before TEM measurements, the samples were dispersed in ethanol. Suspensions of the samples were dropped onto a holey carbon coated copper grid. X-ray photoelectron spectra (XPS) of the CN sample were measured using a PerkinElmer PHI 5000C spectrometer working in the constant analyzer energy mode with $\mathrm{Mg} \mathrm{K} \alpha$ radiation as the excitation source. The carbonaceous C1s line $(284.6 \mathrm{eV})$ was used as a reference to calibrate the binding energies (BE). A thermogravimetric analyzer (Mettler Toledo TGA-SDTA851, Switzerland) was used to determine the thermal stabilities of materials in air and nitrogen atmospheres with a heating rate of $10{ }^{\circ} \mathrm{C} / \mathrm{min}$. Raman spectra were recorded on laser Raman spectrometer (Renishaw inVia Reflex, U.K.) at room temperature using the $514.5 \mathrm{~nm}$ line of an argon ion laser as the excitation source. Fourier transform infrared (FT-IR) spectra of the samples were measured on a Nicolet FT-IR360 spectrometer using the usual $\mathrm{KBr}$ pellet technique. Carbon dioxide temperatureprogrammed desorption $\left(\mathrm{CO}_{2}\right.$-TPD) was carried out on a Micromeritics Chemisorption Analyzer (USA). Before measurements, the samples were first activated at $500{ }^{\circ} \mathrm{C}$ for $1 \mathrm{~h}$ under a helium atmosphere. After the temperature was reduced to $50{ }^{\circ} \mathrm{C}$, the samples were swept by $\mathrm{CO}_{2}$ for $1.5 \mathrm{~h}$, and then the gas was switched to helium to remove the physically adsorbed $\mathrm{CO}_{2}$ molecules, until the baseline was flat. Subsequently, the temperature was gradually increased to $500{ }^{\circ} \mathrm{C}$ with a ramping rate of $10{ }^{\circ} \mathrm{C} / \mathrm{min}$ to obtain the $\mathrm{CO}_{2}-\mathrm{TPD}$ curves.

\section{Results and discussion}

\subsection{Structural and textural properties}

The SAXS pattern (Fig. 1(a)a) of the spherical mesoporous silica MCF template shows five obvious scattering peaks, suggesting a well-resolved cellular foam mesostructure. After CTC and EDA precursors were filled into the mesopore channels and the material was pyrolyzed, the intensity of scattering peaks (Fig. 1(a)b) became a little weaker. Furthermore, the scattering peaks shifted to slightly higher $q$ values, suggesting a small shrinkage of the mesostructure, as a result of the high pyrolysis temperature of $600{ }^{\circ} \mathrm{C}$. The scattering peaks of the mesoporous $\mathrm{CN}$ spheres after the removal of silica by HF (Fig. 1(a)c) became better resolved and further shifted to higher $q$ values. This suggests that the synthesized mesoporous $\mathrm{CN}$ spheres have a well-defined 3-D foam mesostructure replicating the silica template.

Nitrogen sorption isotherms of the silica MCF template (Fig. 1(b)a) show typical type IV curves with a steep $H_{1}$ hysteresis loop in the relative pressure $\left(P / P_{0}\right)$ range of ca. $0.85-0.95$, characteristic of a mesoporous material with large pore size and narrow pore size distribution centered at $\sim 29 \mathrm{~nm}$ (Fig. 1(c)a). Its calculated BET specific surface area and pore volume are as large as $502 \mathrm{~m}^{2} / \mathrm{g}$ and $2.3 \mathrm{~cm}^{3} / \mathrm{g}$, respectively. After the $\mathrm{CN}$ precursors were incorporated into the mesopore channels of the silica MCF template, the BET specific surface area (Fig. 1(b)b) and total pore volume of the resulting mesoporous $\mathrm{CN} /$ silica composites were significantly reduced to $183 \mathrm{~m}^{2} / \mathrm{g}$ and $0.18 \mathrm{~cm}^{3} / \mathrm{g}$, respectively. Furthermore, the steep step in the $\mathrm{N}_{2}$ adsorption isotherm associated with the micropores nearly disappeared, which is consistent with the corresponding pore size distribution (PSD, Fig. 1(c)b) curve. This indicates that the micropores of the silica template are completely filled by the CN composite, which should favor retention of the 3-D mesostructure after removal of the silica. In addition, the pore size of the mesoporous $\mathrm{CN} /$ silica composites decreases to about $24 \mathrm{~nm}$, suggesting that the pore channels of the silica template are not completely filled. After removal of the silica template, the nitrogen sorption isotherms of the mesoporous CN spheres (Fig. 1(b)c) clearly show two hysteresis loops at $P / P_{0}$ of ca. $0.40-0.60$ and 0.85-0.99, suggesting a typical hierarchical mesostructure (bimodal mesopores). Correspondingly, the PSD curve (Fig. 1(c)c) shows two peaks, one narrow peak centered at $4.0 \mathrm{~nm}$ and another broad peak at $43 \mathrm{~nm}$. The former pores may result from the removal of the silica walls and the latter from the partial collapse 


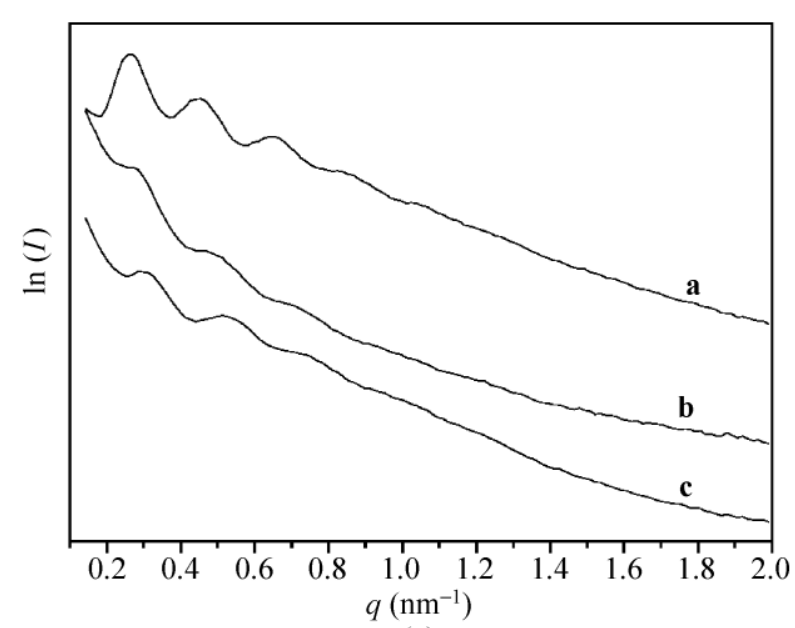

(a)

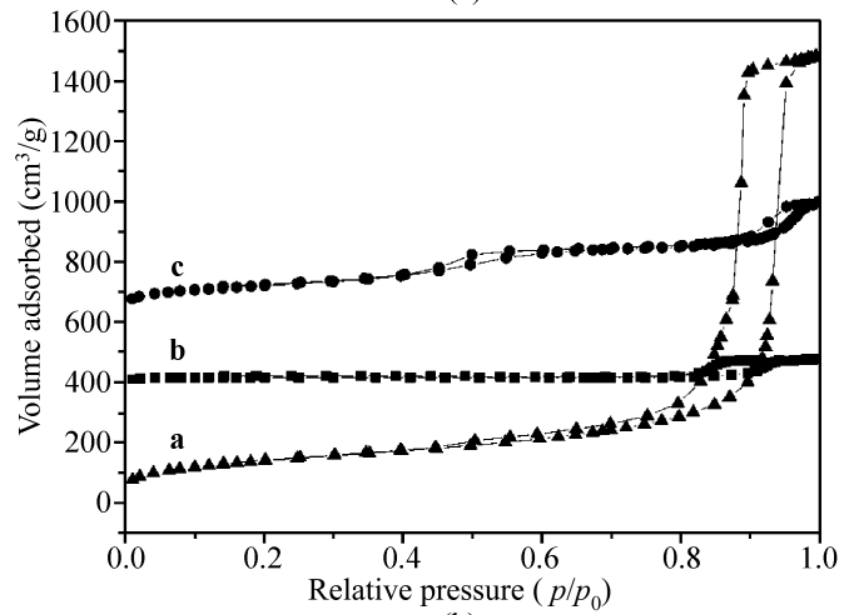

(b)

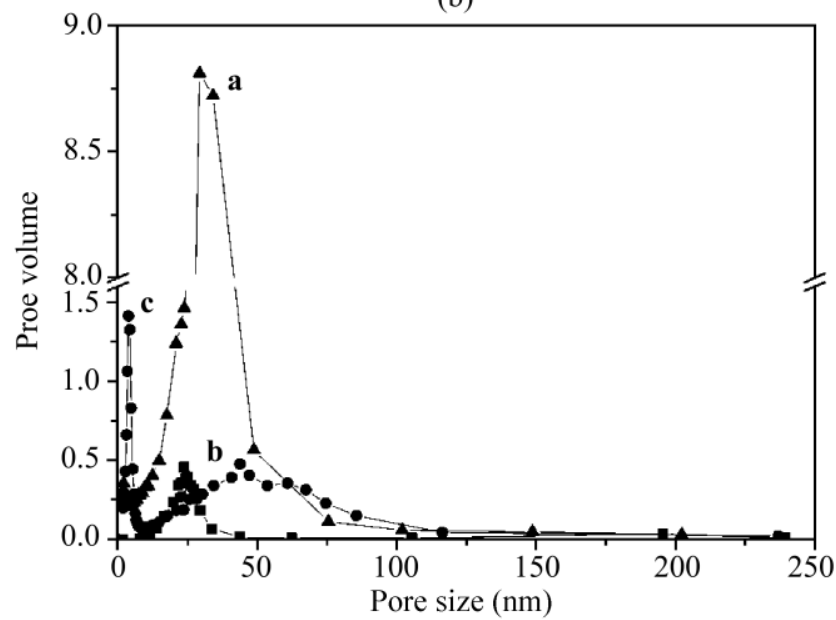

(c)

Figure 1 SAXS patterns (a), nitrogen sorption isotherms (b) and corresponding pore size distributions (c) of a, the spherical mesostructured cellular silica foams which functions as a hard template; b, the mesoporous $\mathrm{CN} /$ silica composites; $\mathbf{c}$, the mesoporous $\mathrm{CN}$ spheres after removal of the silica template of the $\mathrm{CN}$ mesostructures due to the relatively low loading amount. The BET specific surface area, total pore volume and micropore volume of the mesoporous $\mathrm{CN}$ spheres are $550 \mathrm{~m}^{2} / \mathrm{g}, 0.90 \mathrm{~cm}^{3} / \mathrm{g}$, and $0.08 \mathrm{~cm}^{3} / \mathrm{g}$, respectively.

FE-SEM images (Fig. 2) of the silica MCF templates and resulting mesoporous $\mathrm{CN}$ spheres show that the spherical morphology is well replicated and that the diameter of the spheres is ca. $4 \mu \mathrm{m}$. The magnified SEM images of the mesoporous $\mathrm{CN}$ sample obtained after removal of the silica template (Figs. 2(d)-2(f)) clearly show an interconnected and hierarchical 3-D mesostructure. In addition, the pore size is in the range ca. 4.0 to $40 \mathrm{~nm}$, which is consistent with the corresponding nitrogen sorption results. TEM images (Figs. 3(a)-3(c)) of the spherical silica MCF templates and mesoporous $\mathrm{CN}$ replicas show that the foam-like mesostructures are well replicated. In addition to some pores (Fig. 3(b)) arising from the original pores of the silica template, the spherical mesoporous $\mathrm{CN}$ replicas also contain some "sphere-like" particles, suggesting a faithful replication of the template.

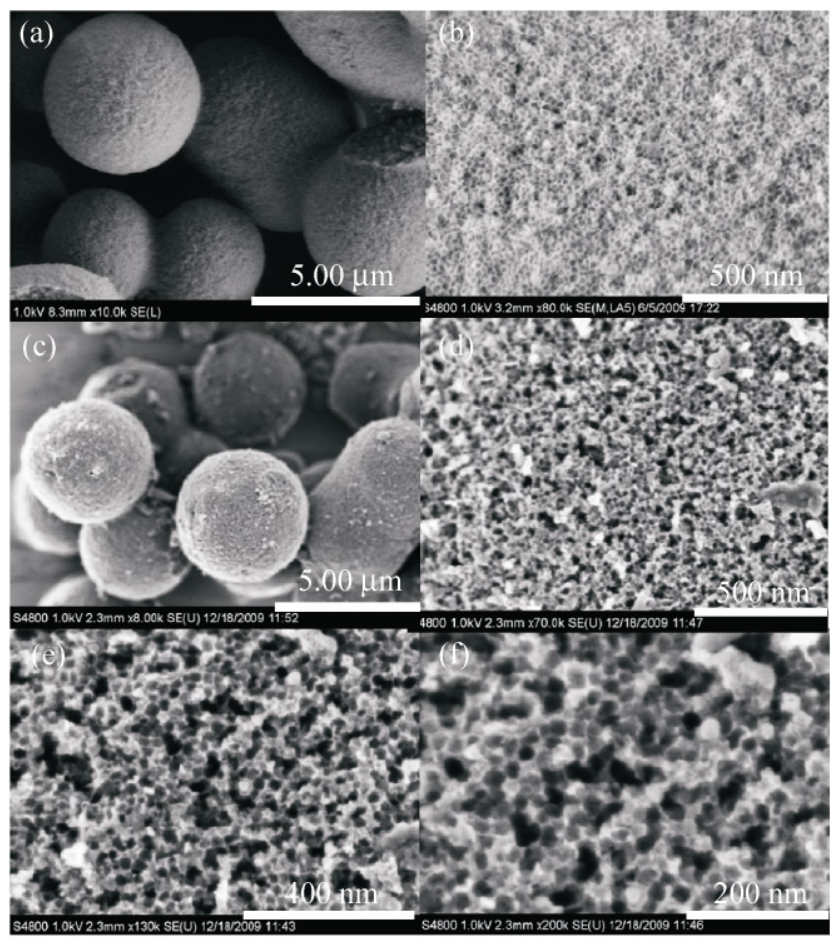

Figure 2 FE-SEM images of (a), (b) the spherical MCFs, and (c)-(f) the mesoporous $\mathrm{CN}$ spheres synthesized by the nanocasting approach using the silica MCFs as a hard template 


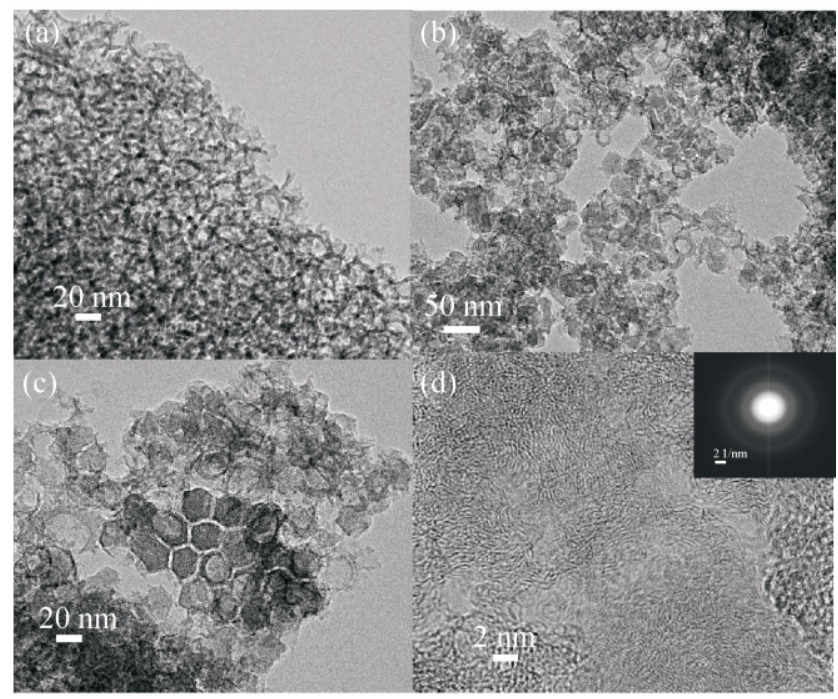

Figure 3 TEM images of (a) the spherical mesostructured cellular silica foams, and (b), (c) the mesoporous carbon nitride materials templated by the silica MCFs. A high-resolution TEM image lof the $\mathrm{CN}$ material is shown in (d) and the inset is the corresponding selected area electron diffraction pattern (SAED)

Furthermore, some small mesopores of diameter ca. $4 \mathrm{~nm}$ can also be observed (Fig. 3(c)), which result from the removal of the silica pore walls. These results are consistent with the nitrogen sorption and SEM results. The HRTEM images and corresponding SAED pattern (Fig. 3(d) and Fig. S-2 in the ESM) demonstrate that the pore walls have a partly graphitized and glasscarbon-like structure. Moreover, the wide-angle XRD pattern (Fig. 4(a)) shows an obvious diffraction peak at ca. $25.4^{\circ}$ corresponding to an interlayer $d$ spacing of $\sim 0.35 \mathrm{~nm}$, indicating that there is turbostratic ordering of carbon and nitrogen atoms in the $\mathrm{CN}$ graphene layers, which is similar to that in bulk $\mathrm{CN}$ materials reported previously $[9,10]$. In addition, in the Raman spectrum of the mesoporous CN sample the intensity of the $G$ band is higher than that of the $D$ band (Fig. 4(b)), suggesting that many $\mathrm{sp}^{2}$ hybridized carbon species are present in the graphitized pore walls, consistent with the TEM and XRD results.

The thermogravimetric (TG) measurements (Fig. 5(a)) show that the decomposition of the mesoporous $\mathrm{CN}$ spheres in air begins at ca. $460{ }^{\circ} \mathrm{C}$ and is complete at ca. $650{ }^{\circ} \mathrm{C}$. The maximum weight loss occurs at a temperature of $570{ }^{\circ} \mathrm{C}$, associated with the release of many small molecules, such as $\mathrm{CO}_{2}, \mathrm{H}_{2} \mathrm{O}$, and $\mathrm{N}_{2}$, due to the reaction between $\mathrm{CN}$ and oxygen. In a nitrogen atmosphere, the main mass loss of the mesoporous $\mathrm{CN}$ material occurs at ca. $600{ }^{\circ} \mathrm{C}$ (Fig. 5(b)), which can be attributed to the release of small molecules, including $\mathrm{N}_{2}$ and $\mathrm{NH}_{3}$. It can be concluded that a nitrogen atmosphere increases the thermal stability of the material.

The XPS survey spectrum (Fig. 6(a)) of the mesoporous $\mathrm{CN}$ sample shows strong signals from $\mathrm{C}, \mathrm{N}$, and $\mathrm{O}$ elements. $\mathrm{No} \mathrm{Cl}$ and $\mathrm{Si}$ signals can be observed, suggesting that $\mathrm{Cl}$-containing and silica species are almost completely removed during the HF etching and pyrolysis process. The presence of $\mathrm{O}$ species may arise from oxidation of the precursors during the process.

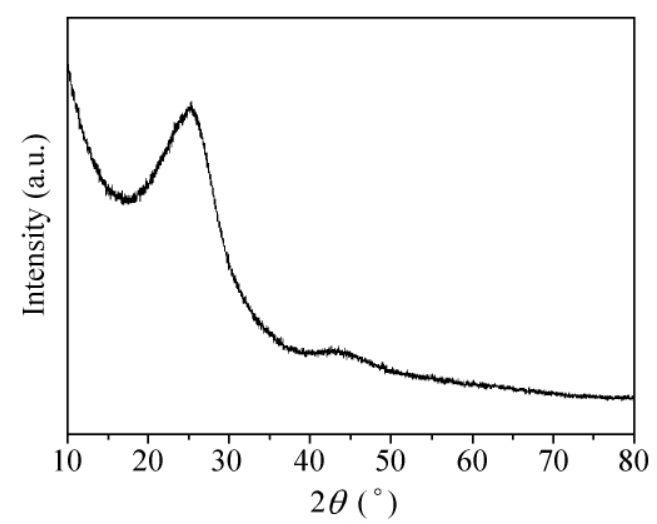

(a)

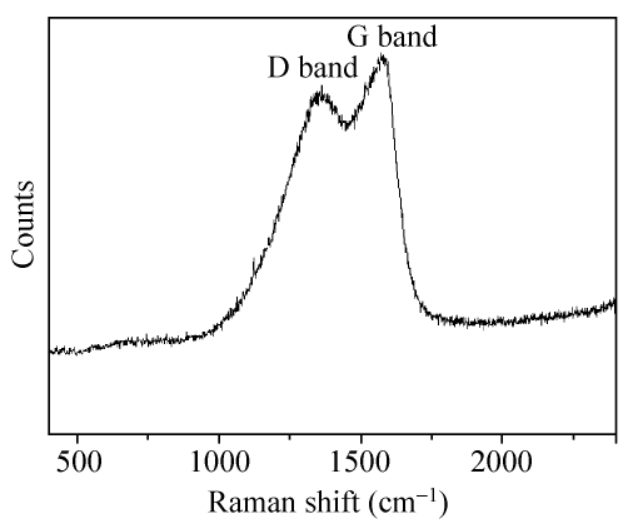

(b)

Figure 4 The wide-angle XRD pattern (a) and Raman spectrum (b) of the mesoporous CN spheres synthesized by the nanocasting approach using the silica MCFs as a hard template 
The $\mathrm{C}$ 1s peak (Fig. 6(b)) can be deconvoluted into four peaks at 289.3, 287.5, 285.7, and $284.1 \mathrm{eV}$. The lowest binding energy peak $(284.1 \mathrm{eV})$ can be assigned to pure graphitic sites in a $\mathrm{CN}$ matrix $[8,9,29-31]$. The peak at $285.7 \mathrm{eV}$ can be attributed to the $\mathrm{sp}^{2} \mathrm{C}$ atom bonded

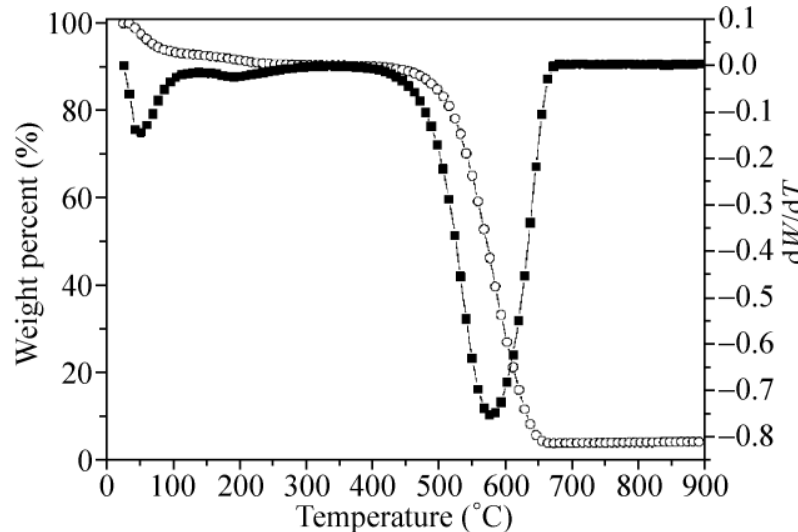

(a) to $\mathrm{N}$ in an aromatic ring [30]. In addition, the peaks at 287.5 and $289.3 \mathrm{eV}$ suggest the formation of $\mathrm{sp}^{3}$ hybridized $\mathrm{C}$ atoms and $\mathrm{sp}^{2} \mathrm{C}$ atoms bonded to $\mathrm{NH}_{2}$ groups, respectively [29]. Furthermore, two peaks are observed in the $\mathrm{N}$ 1s spectrum (Fig. 6(c)). The higher

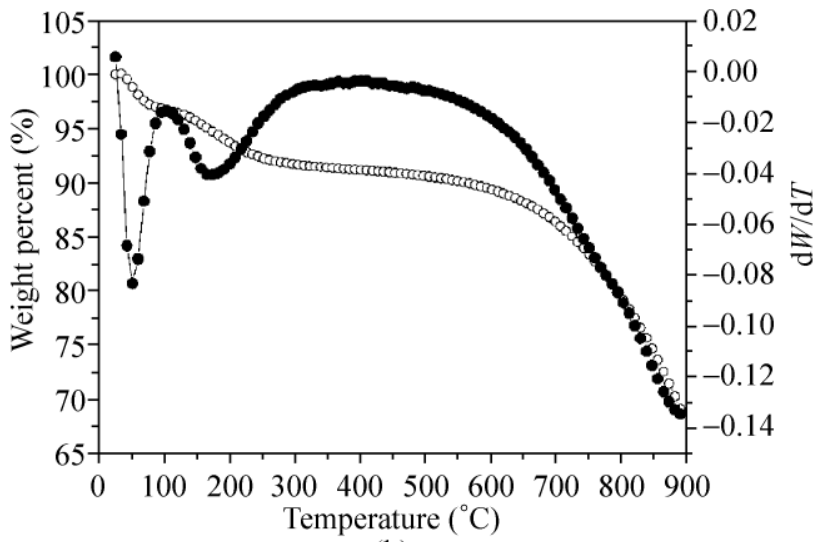

(b)

Figure 5 The thermogravimetric curves of the mesoporous CN spheres in air (a) and nitrogen (b) atmospheres

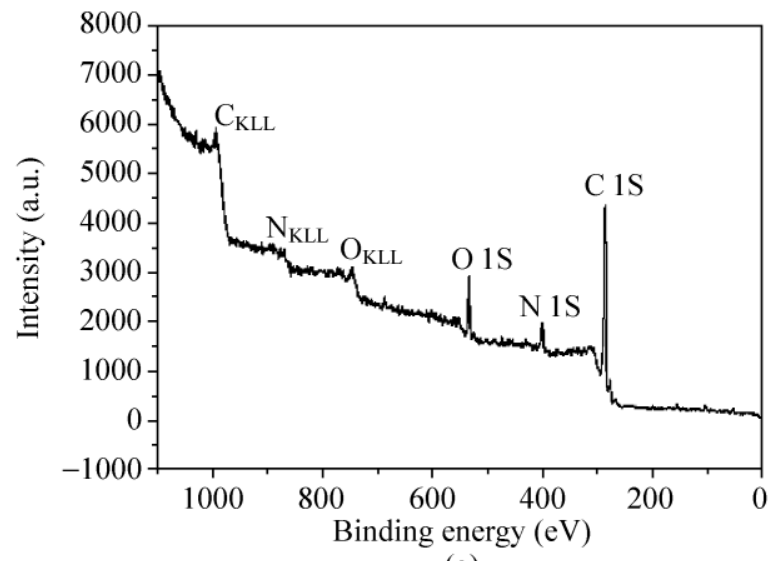

(a)

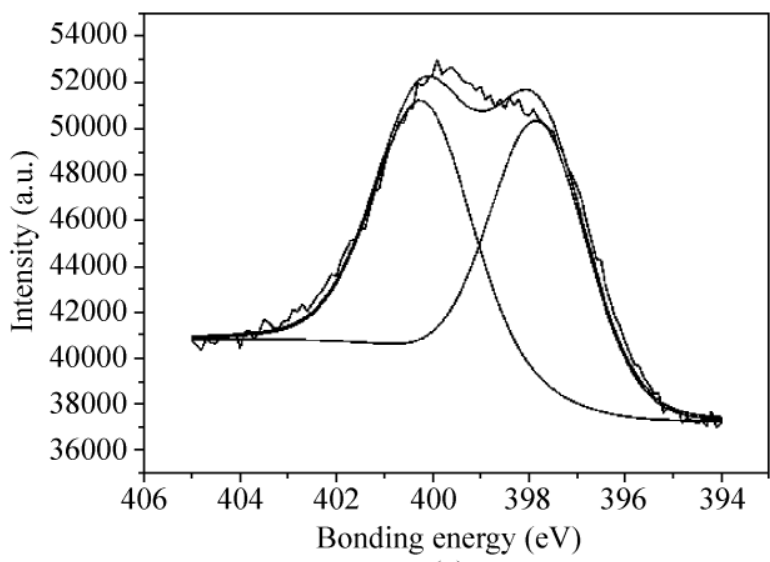

(c)

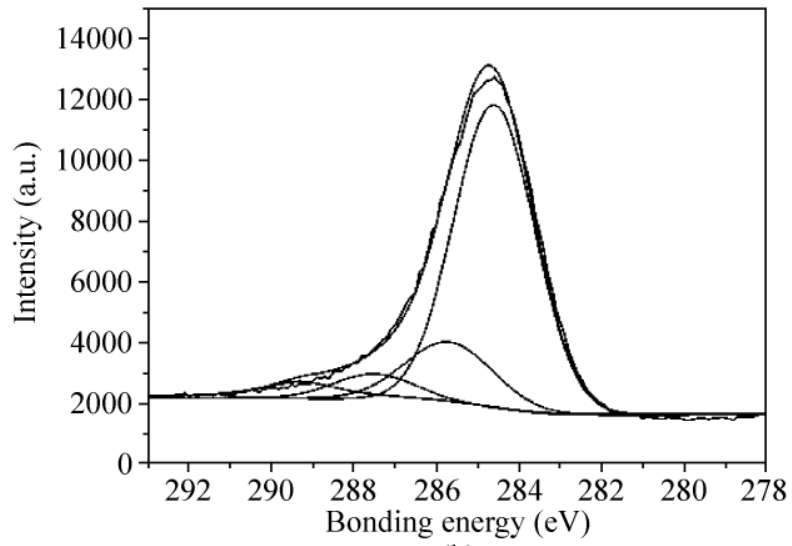

(b)

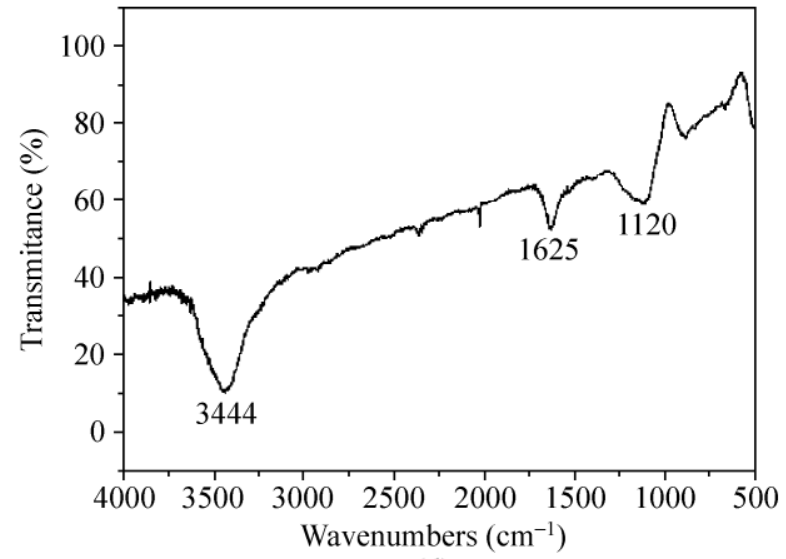

(d)

Figure 6 XPS spectra of the mesoporous CN spheres: (a), survey spectrum; (b), C 1s spectrum; and (c), N 1s spectrum; and (d) the FT-IR spectrum 
binding energy peak $(400.2 \mathrm{eV})$ corresponds to $\mathrm{N}$ atoms trigonally bonded with $\mathrm{sp}^{2}$ or $\mathrm{sp}^{3} \mathrm{C}$ atoms $[8,9]$. The other peak $(397.8 \mathrm{eV})$ can be assigned to $\mathrm{sp}^{2} \mathrm{~N}$ atoms bonded to carbon atoms $[8,9]$. These assignments are consistent with the $\mathrm{C} 1 \mathrm{~s}$ spectrum. Elemental analysis gave the $\mathrm{C}, \mathrm{N}, \mathrm{O}$, and $\mathrm{H}$ contents of the mesoporous $\mathrm{CN}$ spheres as ca. 69.0, 17.8, 10.2, and $3.0 \mathrm{wt} \%$, respectively, indicating that a significant number of nitrogen atoms are bonded to $\mathrm{C}$ atoms.

The FT-IR spectrum (Fig. 6(d)) of the mesoporous $\mathrm{CN}$ spheres shows two strong bands at 1120 and $1625 \mathrm{~cm}^{-1}$, which can be ascribed to aromatic C-N stretching bonds and aromatic ring modes, respectively. In addition, the weaker band at $3444 \mathrm{~cm}^{-1}$ may be related to $\mathrm{N}-\mathrm{H}$ or $\mathrm{O}-\mathrm{H}$ stretching vibrations or water molecules. These results suggest that the mesoporous $\mathrm{CN}$ spheres are mainly composed of pyridine and benzene rings interconnected by nitrogen atoms.

\section{2 $\mathrm{CO}_{2}$ capture performance}

The adsorption isotherms of the mesoporous $\mathrm{CN}$ spheres (Fig. 7(a)) show that after adsorption for $150 \mathrm{~min}, \mathrm{CO}_{2}$ uptake reaches $2.90 \mathrm{mmol} / \mathrm{g}$ at $25^{\circ} \mathrm{C}$. When the temperature was increased to $75^{\circ} \mathrm{C}$, the uptake greatly decreased to $0.97 \mathrm{mmol} / \mathrm{g}$. In addition, it can be observed that the material exhibits relatively slow $\mathrm{CO}_{2}$ adsorption kinetics, which can be attributed to the large number of micropores $\left(0.08 \mathrm{~cm}^{3} / \mathrm{g}\right)$ formed on the pore walls since their small pore sizes limit $\mathrm{CO}_{2}$ diffusion. For comparison, mesoporous pristine carbon spheres were synthesized by using the same silica
MCF template and a similar nanocasting approach. The SAXS patterns show that the pristine carbon spheres have a similar 3-D mesostructure to the counterpart mesoporous $\mathrm{CN}$ sample (Fig. S-1(a) in the ESM). Their BET specific surface area and pore volume are $737 \mathrm{~m}^{2} / \mathrm{g}$ and $0.90 \mathrm{~cm}^{3} / \mathrm{g}$, respectively (Fig. S-1(b) in the ESM). The $\mathrm{CO}_{2}$ uptake $(2.50 \mathrm{mmol} / \mathrm{g})$ of the pristine carbon material (Fig. 7(b)) was similar to that of the mesoporous $\mathrm{CN}$ sample at $25^{\circ} \mathrm{C}$. However, when the temperature was increased to $75{ }^{\circ} \mathrm{C}$, its $\mathrm{CO}_{2}$ uptake decreased dramatically to $0.30 \mathrm{mmol} / \mathrm{g}$ (Fig. 7(b)), which is much lower than the corresponding value for the mesoporous $\mathrm{CN}$ spheres, suggesting that there is a weak interaction between the carbon pore walls and $\mathrm{CO}_{2}$ molecules.

The cycling stability of the mesoporous $\mathrm{CN}$ spheres was also investigated (Fig. 8(a)), since this is an important factor in terms of practical application in $\mathrm{CO}_{2}$ capture. After adsorption for $60 \mathrm{~min}$, the $\mathrm{CO}_{2}$ uptake for the first cycle was $\sim 1.70 \mathrm{mmol} / \mathrm{g}$. However, the capture capacity in the second cycle decreased to $1.07 \mathrm{mmol} / \mathrm{g}$, mainly due to the difference between the activation processes in the first and second cycles. The $\mathrm{CO}_{2}$ uptake in the second to fourth cycles, which involve the same activation process, was maintained in the range of $1.07-0.90 \mathrm{mmol} / \mathrm{g}$, suggesting a good cycling stability of the material as a $\mathrm{CO}_{2}$ adsorbent.

The high nitrogen content (17.8 $\mathrm{wt} \%)$, which can be mainly ascribed to the pyridine rings, endows the spherical mesoporous $\mathrm{CN}$ materials with abundant Lewis base sites. This can be confirmed by the obvious

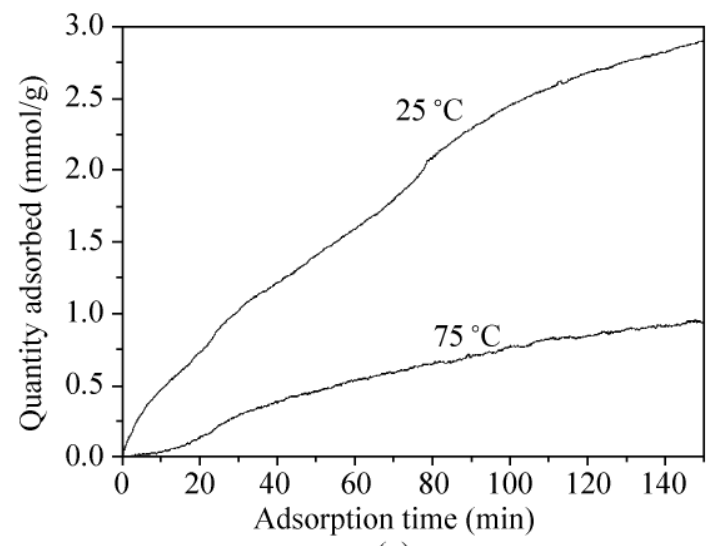

(a)

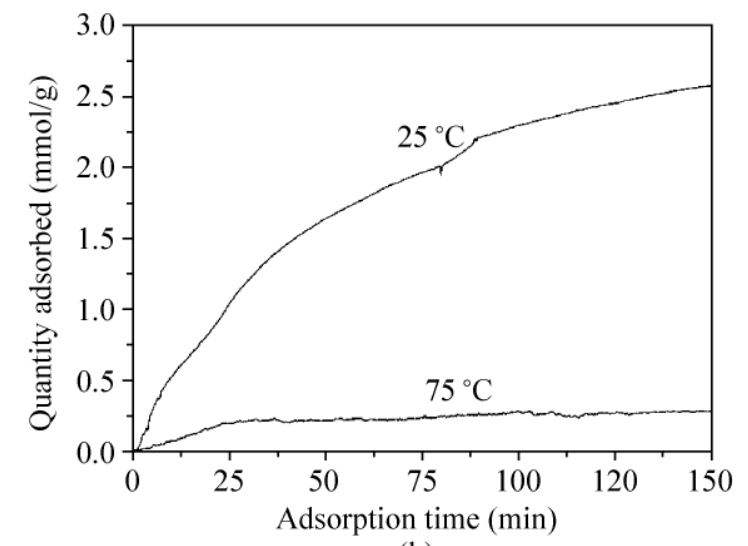

(b)

Figure $7 \quad \mathrm{CO}_{2}$-capture capacities of (a) the mesoporous $\mathrm{CN}$ materials and (b) the pristine carbon spheres at 25 and $75{ }^{\circ} \mathrm{C}$ 


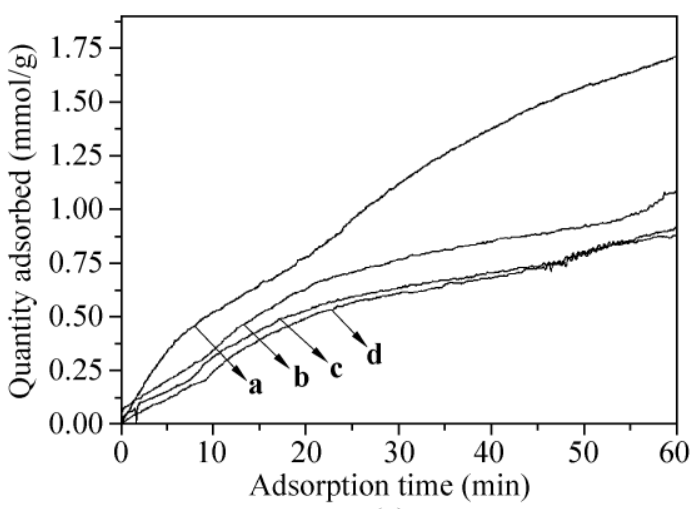

(a)

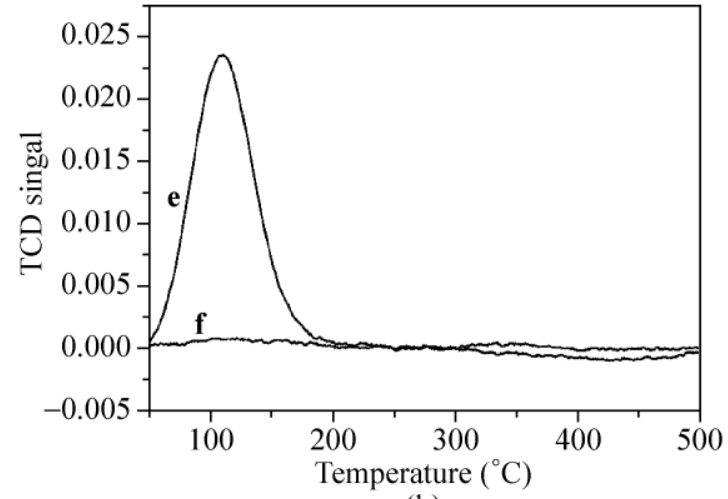

(b)

Figure 8 (a) Cycling stability of the mesoporous $\mathrm{CN}$ spheres when used as a $\mathrm{CO}_{2}$ adsorbent: $\mathbf{a}$, the first cycle; $\mathbf{b}$, the second cycle; $\mathbf{c}$, the third cycle; $\mathbf{d}$, the fourth cycle. (b) $\mathrm{CO}_{2}$-TPD curves: e, mesoporous $\mathrm{CN}$ spheres and $\mathbf{f}$, pristine mesoporous carbon spheres

desorption peak in the corresponding $\mathrm{CO}_{2}$-TPD curve (Fig. 8(b)) centered at $110{ }^{\circ} \mathrm{C}$, suggesting a relatively weak basicity and low $\mathrm{CO}_{2}$-desorption temperature. These basic sites are responsible for the high extent of capture of $\mathrm{CO}_{2}$ molecules due to the formation of weak covalent bonds between $\mathrm{CO}_{2}$ molecules and the basic sites. Both the specific surface area and basic sites play an important role in improving the capture performance. Furthermore, the existence of a large number of micropores and small mesopores in the spherical $\mathrm{CN}$ materials also contribute to its excellent $\mathrm{CO}_{2}$ capture performance, owing to the capillary condensation effect [32]. In contrast, the $\mathrm{CO}_{2}$-TPD curve of the pristine mesoporous carbon spheres does not show any obvious desorption peak, suggesting the absence of any basic sites (see Fig. 8(b)f). In this case, physisorption alone is responsible for $\mathrm{CO}_{2}$ capture. As a result, the adsorption capacity of the material can only be increased by increasing the specific surface area.

The capture capacity $(2.90 \mathrm{mmol} / \mathrm{g})$ of the mesoporous $\mathrm{CN}$ spheres results from both physical and chemical adsorption at $25^{\circ} \mathrm{C}$. When the temperature is increased to $75^{\circ} \mathrm{C}$, some of physically captured $\mathrm{CO}_{2}$ molecules escape from the surface of the pore walls, and therefore the $\mathrm{CO}_{2}$ uptake decreases markedly to $0.97 \mathrm{mmol} / \mathrm{g}$. In this case, a fraction of the $\mathrm{CO}_{2}$ molecules are still bonded on the surface due to the formation of weak bonds. The 3-D hierarchical mesostructure also makes a great contribution to the efficiency of the capture process, because it may facilitate the diffusion of $\mathrm{CO}_{2}$ in the pore channels and improve the utilization efficiency of surface area and basic sites [33,34]. Moreover, the oxygen-containing groups formed during the synthesis process also increase $\mathrm{CO}_{2}$ capture, because they may also form Lewis base sites on the pore walls. Although the pristine mesoporous carbon spheres have a similar capture capacity to the mesoporous $\mathrm{CN}$ materials at $25{ }^{\circ} \mathrm{C}$, increasing adsorption temperatures results in a significant decrease in $\mathrm{CO}_{2}$ uptake owing to the weak interactions. In addition, because the mesoporous $\mathrm{CN}$ spheres have good thermal stability and a relatively low $\mathrm{CO}_{2}$ desorption temperature $\left(110{ }^{\circ} \mathrm{C}\right)$, the framework and basic sites both remain essentially unchanged during the recycling processes. As a result, the material has excellent cycling stability and long working life as an adsorbent. This demonstrates that the mesoporous $\mathrm{CN}$ spheres are a very promising candidate for $\mathrm{CO}_{2}$ capture.

\section{Conclusions}

Hierarchical mesoporous $\mathrm{CN}$ spheres have been successfully synthesized using spherical silica MCFs as a hard template, and ethylenediamine and carbon tetrachloride as precursors by a nanocasting process. The spherical $\mathrm{CN}$ material has a particle diameter of ca. $4 \mu \mathrm{m}$ and a 3-D hierarchical mesostructure with pore sizes centered at $\sim 4.0$ and $43 \mathrm{~nm}$. Its specific surface area and pore volume are $550 \mathrm{~m}^{2} / \mathrm{g}$ and $0.90 \mathrm{~cm}^{3} / \mathrm{g}$, respectively. Elemental analysis shows that it has a high nitrogen content $(17.8 \mathrm{wt} \%)$, endowing it 
with an abundance of basic sites. The pore walls are mainly composed of benzene and pyridine rings interconnected by nitrogen atoms, exhibiting a partly graphitized structure. The mesoporous $\mathrm{CN}$ spheres show excellent $\mathrm{CO}_{2}$ capture performance and cycling stability, with a $\mathrm{CO}_{2}$ uptake as high as $2.90 \mathrm{mmol} / \mathrm{g}$; this can be attributed to the high specific surface area, abundant nitrogen- and oxygen-containing basic sites, hierarchical mesostructure, and stable framework.

\section{Acknowledgements}

This work was supported by the National Natural Science Foundation of China (NSFC) (Nos. 2089012, 20721063, 20821140537, 20871030), State Key Basic Research Program of PRC (Nos. 2006CB932302 and 2009AA033701), Shanghai Leading Academic Discipline Project (No. B108), and Science \& Technology Commission of Shanghai Municipality (No. 08DZ2270500). C. S. Ha also thanks the National Research Foundation (NRF) of Korea for support through the Korea-China Joint Research Center Program on Mesoporous Thin Films (No. K20803001459-10B1200-00310) and the Acceleration Research Program (No. 2010-0000790).

Electronic Supplementary Material: Supplementary material including the process for preparation of the resol precursor, the SAXS patterns and nitrogen sorption isotherms of the spherical mesostructured cellular silica foams and replicated pristine mesoporous carbon spheres and HRTEM images of the $\mathrm{CN}$ spheres is available in the online version of this article at http://dx.doi.org/ 10.1007/s12274-010-0023-7 and is accessible free of charge.

Open Access: This article is distributed under the terms of the Creative Commons Attribution Noncommercial License which permits any noncommercial use, distribution, and reproduction in any medium, provided the original author(s) and source are credited.

\section{References}

[1] Kawaguchi, M.; Yagi, S.; Enomoto, H. Chemical preparation and characterization of nitrogen-rich carbon nitride powders. Carbon 2004, 42, 345-350.
[2] Khabashesku, V. N.; Zimmerman, J. L.; Margrave, J. L. Powder synthesis and characterization of amorphous carbon nitride. Chem. Mater. 2000, 12, 3264-3270.

[3] Huynh, M. H. V.; Hiskey, M. A.; Archuleta, J. G.; Roemer, E. L. Preparation of nitrogen-rich nanolayered, nanoclustered, and nanodendritic carbon nitrides. Angew. Chem. Int. Ed. 2005, 44, 737-739.

[4] Pevida, C.; Drage, T. C.; Snape, C. E. Silica-templated melamine-formaldehyde resin derived adsorbents for $\mathrm{CO}_{2}$ capture. Carbon 2008, 46, 1464-1474.

[5] Goettmann, F.; Fischer, A.; Antonietti, M.; Thomas, A. Mesoporous graphitic carbon nitride as a versatile, metalfree catalyst for the cyclisation of functional nitriles and alkynes. New J. Chem. 2007, 31, 1455-1460.

[6] Kim, M.; Hwang, S.; Yu, J. -S. Novel ordered nanoporous graphitic $\mathrm{C}_{3} \mathrm{~N}_{4}$ as a support for Pt-Ru anode catalyst in direct methanol fuel cell. J. Mater. Chem. 2007, 17, 1656-1659.

[7] Chen, X.; Jun, Y. -S.; Takanabe, K.; Maeda, K.; Domen, K.; Fu, X.; Antonietti, M.; Wang, X. Ordered mesoporous SBA-15 type graphitic carbon nitride: A semiconductor host structure for photocatalytic hydrogen evolution with visible light. Chem. Mater. 2009, 21, 4093-4095.

[8] Vinu, A. Two-dimensional hexagonally-ordered mesoporous carbon nitrides with tunable pore diameter, surface area and nitrogen content. Adv. Funct. Mater. 2008, 18, 816-827.

[9] Vinu, A.; Ariga, K.; Mori, T.; Nakanishi, T.; Hishita, S.; Golberg, D.; Bando, Y. Preparation and characterization of well-ordered hexagonal mesoporous carbon nitride. $A d v$. Mater. 2005, 17, 1648-1652.

[10] Jin, X.; Balasubramanian, V. V.; Selvan, S. T.; Sawant, D. P.; Chari, M. A.; Lu, G. Q.; Vinu, A. Highly ordered mesoporous carbon nitride nanoparticles with high nitrogen content: A metal-free basic catalyst. Angew. Chem. Int. Ed. 2009, 48, 7884-7887.

[11] Thomas, A.; Fischer, A.; Goettmann, F.; Antonietti, M.; Muller, J. -O.; Schlogl, R.; Carlsson, J. M. Graphitic carbon nitride materials: Variation of structure and morphology and their use as metal-free catalysts. J. Mater. Chem. 2008, 18, 4893-4908.

[12] Fischer, A.; Antonietti, M.; Thomas, A. Growth confined by the nitrogen source: Synthesis of pure metal nitride nanoparticles in mesoporous graphitic carbon nitride. Adv. Mater. 2007, 19, 264-267.

[13] Jun, Y. -S.; Hong, W. H.; Antonietti, M.; Thomas, A. Mesoporous, 2D hexagonal carbon nitride and titanium nitride/carbon composites. Adv. Mater. 2009, 21, 4270-4274.

[14] Liu, L.; Ma, D.; Zheng, H.; Li, X.; Cheng, M.; Bao, X. Synthesis and characterization of microporous carbon nitride. Micropor. Mesopor. Mater. 2008, 110, 216-222. 
[15] Fischer, A.; Jun, Y. -S.; Thomas, A.; Antonietti, M. Synthesis of high-surface-area TiN/carbon composite materials with hierarchical porosity via "reactive templating". Chem. Mater. 2008, 20, 7383-7389.

[16] Figueroa, J. D.; Fout, T.; Plasynski, S.; Mcllvried, H.; Srivastava, R. D. Advances in $\mathrm{CO}_{2}$ capture technologyThe US Department of Energy's Carbon Sequestration Program. Int. J. Greenhouse Gas Control 2008, 2, 9-20.

[17] Seki, T.; Kokubo, Y.; Ichikawa, S.; Suzuki, T.; Kayaki, Y.; Ikariya, T. Mesoporous silica-catalysed continuous chemical fixation of $\mathrm{CO}_{2}$ with $N, N$,-dimethylethylenediamine in supercritical $\mathrm{CO}_{2}$ : The efficient synthesis of 1,3-dimethyl-2imidazolidinone. Chem. Commun. 2009, 349-351.

[18] Zhao, C.; Chen, X.; Zhao, C. $\mathrm{CO}_{2}$ absorption using dry potassium-based sorbents with different supports. Energy Fuels 2009, 23, 4683-4687.

[19] Thote, J. A.; Iyer, K. S.; Chatti, R.; Labhsetwar, N. K.; Biniwale, R. B.; Rayalu, S. S. In situ nitrogen enriched carbon for carbon dioxide capture. Carbon 2010, 48, 396-402.

[20] Drage, T. C.; Arenillas, A.; Smith, K. M.; Pevida, C.; Piippo, S.; Snape, C. E. Preparation of carbon dioxide adsorbents from the chemical activation of urea-formaldehyde and melamine-formaldehyde resins. Fuel 2007, 86, 22-31.

[21] Liang, Z.; Fadhel, B.; Schneider, C. J.; Chaffee, A. L. Adsorption of $\mathrm{CO}_{2}$ on mesocellular siliceous foam iteratively functionalized with dendrimers. Adsorption 2009, $15,429-437$.

[22] Zelenak, V.; Halamova, D.; Gaberova, L.; Bloch, E.; Llewellyn, P. Amine-modified SBA-12 mesoporous silica for carbon dioxide capture: Effect of amine basicity on sorption properties. Micropor. Mesopor. Mater. 2008, 116, 358-364.

[23] Rinker, E.; Ashour, S. S.; Sandall, O. C. Absorption of carbon dioxide into aqueous blends of diethanolamine and methyldiethanolamine. Ind. Eng. Chem. Res. 2000, 39, 4346-4356.

[24] Kohl, A.; Nielsen, R. Gas Purification, 5th ed.; Gulf Publishing Co.: Houston, 1997.
[25] Pevida, C.; Plaza, M. G.; Arias, B.; Fermoso, J.; Rubiera, F.; Pis, J. J. Surface modification of activated carbons for $\mathrm{CO}_{2}$ capture. Appl. Surf. Sci. 2008, 254, 7165-7172.

[26] Plaza, M. G.; Pevida, C.; Arenillas, A.; Rubiera, F.; Pis, J. J. $\mathrm{CO}_{2}$ capture by adsorption with nitrogen enriched carbons. Fuel 2007, 86, 2204-2212.

[27] Han, Y.; Lee, S. S.; Ying, J. Y. Spherical siliceous mesocellular foam particles for high-speed size exclusion chromatography. Chem. Mater. 2007, 19, 2292-2298.

[28] Meng, Y.; Gu, D.; Zhang, F.; Shi, Y.; Yang, H.; Li, Z.; Yu, C.; Tu, B.; Zhao, D. Y. Ordered mesoporous polymers and homologous carbon frameworks: Amphiphilic surfactant templating and direct transformation. Angew. Chem. Int. Ed. 2005, 44, 7053-7059.

[29] Sanchez-Lopez, J. C.; Donnet, C.; Lefebvre, F.; FernandezRamos, C.; Fernandez, A. Bonding structure in amorphous carbon nitride: A spectroscopic and nuclear magnetic resonance study. J. Appl. Phys. 2001, 90, 675-681.

[30] Marton, D.; Boyd, K. J.; Al-Bayati, A. H.; Todorov, S. S.; Rabalais, J. W. Carbon nitride deposited using energetic species-A2-phase system. Phys. Rev. Lett. 1994, 73, 118-121.

[31] Chen, Y. H.; Tay, B. K.; Lau, S. P.; Shi, X.; Qiao, X. L.; Chen, J. G.; Wu, Y. P.; Sun, Z. H.; Xie, C. S. Synthesis of superhard and elastic carbon nitride films by filtered cathodic vacuum arc combined with radio frequency ion beam source. J. Mater. Res. 2002, 17, 521-524.

[32] Zelenák, V.; Badanicová, M.; Halamová, D.; Cejka, J.; Zukal, A.; Murafa, N.; Goerigk, G. Amine-modified ordered mesoporous silica: Effect of pore size on carbon dioxide capture. Chem. Eng. J. 2008, 144, 336-342.

[33] Chen, C.; Yang, S. -T.; Ahn, W. -S.; Ryoo, R. Amineimpregnated silica monolith with a hierarchical pore structure: enhancement of $\mathrm{CO}_{2}$ capture capacity. Chem. Commun. 2009, 3627-3629.

[34] Holland, B. T.; Abrams, L.; Stein, A. Dual templating of macroporous silicates with zeolitic microporous frameworks. J. Am. Chem. Soc. 1999, 121, 4308-4309. 